\title{
Childhood Emotional Maltreatment and Problematic Social Media Use Among Adolescents: The Mediating Role of Body Image Dissatisfaction
}

\author{
Kagan Kircaburun ${ }^{1} \cdot$ Mark D. Griffiths $^{2}$ (D) Joel Billieux ${ }^{3}$ \\ Published online: 16 January 2019 \\ (C) The Author(s) 2019
}

\begin{abstract}
Preliminary evidence suggests that childhood maltreatment is associated with higher problematic social media use (PSMU). It has also been established that childhood emotional maltreatment (CEM) is associated with body image dissatisfaction (BID). However, the direct and indirect impacts of CEM on PSMU via BID remain untested. The present study examined these direct and indirect relationships among a sample of 385 adolescents (mean age 15.62 years, range 14-18 years). Results indicated that female adolescents had higher levels of CEM, BID, and PSMU compared to males. Structural equation modeling indicated that CEM was indirectly associated with PSMU via BID among males. However, only BID was positively associated with PSMU among females. The findings are in accordance with theoretical models suggesting that individuals' core characteristics including early childhood experiences and psychopathological factors are associated with different types of specific internet-use disorders.
\end{abstract}

Keywords Problematic social media use · Childhood maltreatment · Trauma · Body image · Adolescence $\cdot$ Internet addiction $\cdot$ Problematic internet use

Mark D. Griffiths

mark.griffiths@ntu.ac.uk

Kagan Kircaburun

kircaburunkagan@gmail.com

Joel Billieux

joel.billieux@uni.lu

1 Computer and Instructional Technologies Department, Duzce University, Duzce, Turkey

2 International Gaming Research Unit, Psychology Department, Nottingham Trent University, Nottingham, UK

3 Addictive and Compulsive Behaviours Lab, Institute for Health and Behaviour, University of Luxembourg, Esch-sur-Alzette, Luxembourg 
Social media is broadly defined as those forms of electronic communication (such as websites for social networking and microblogging) through which users create online communities to share information, ideas, personal messages, and other content (such as pictures or videos) (Merriam-Webster Dictionary 2018). Social media has become one of the most popular social tools worldwide because of the multiple opportunities they offer to individuals. According to the latest online usage statistics, more than two-thirds of internet users and one-third of all individuals living in the world actively use social media (Statista 2017). Although social media use has numerous benefits including optimizing communication, maintaining existing relationships, and providing up-to-date information (Horzum 2016), a minority of its users appear to be unable to control themselves and display problematic behavior concerning their social media use, experiencing various types of detrimental social, emotional, or psychological effects (Carbonell and Panova 2017; Kuss and Griffiths 2017).

Despite the growing body of literature examining the associations between childhood traumatic experiences with problematic internet use (e.g., Dalbudak et al. 2014; Koronczai et al. 2013; Schimmenti et al. 2017), little is known about the effects of these adverse experiences on problematic social media use (PSMU). Although internet-related disorders overlap with each other up to some point (Montag et al. 2015), individuals typically display distinct forms of specific internet-use disorders that should be considered independently from one another (Baggio et al. 2018; Balakrishnan and Griffiths 2017; Brand et al. 2016; Kircaburun and Griffiths 2018).

It has been claimed that childhood trauma is the chief predictor of lifetime DSM-IV disorders (Kessler et al. 2010), including higher vulnerability to addictive disorders (Thege et al. 2017). Despite the high prevalence of emotional maltreatment in children (Didie et al. 2006; Sansone et al. 1995), research has focused more on sexual and physical abuse (Hagborg et al. 2017; Mills et al. 2015). Childhood emotional maltreatment (CEM) occurs when a children do not receive needed feelings of love, belonging, and support, and/or is exposed to humiliating verbal assaults or demeaning behaviors that will impair their sense of worth and wellbeing (Bernstein et al. 2003).

According to the Interaction-Person-Cognition-Execution (I-PACE) model (Brand et al. 2016), early detrimental and traumatizing childhood experiences are among the core elements that promote technology-mediated problematic behaviors such as PSMU. Individuals with a history of CEM might try to deal with their social, emotional, and/or psychological problems from their adverse childhood experiences (Maguire et al. 2015) via excessive use of social network sites. For instance, individuals experiencing CEM (compared to those who do not) report elevated levels of depression and social anxiety later in life and higher feelings of hopelessness (Hamilton et al. 2013). Furthermore, depression and social anxiety are two consistent predictors of PSMU (Wegmann and Brand 2016). Consequently, it is reasonable to expect that adolescents who have experienced CEM are susceptible to excessive social media use as a way of coping with such aforementioned problems and as an escape from unpleasant affective states (Schimmenti and Caretti 2010; Schimmenti et al. 2017). A recent study showed that childhood maltreatment (i.e., physical, sexual, and emotional abuse, and physical and emotional neglect) predicted higher PSMU symptoms via depressive symptoms and maladaptive attachment styles (Worsley et al. 2018). However, the potential role of CEM on PSMU remains untested.

Given the impaired sense of self-worth and self-esteem frequently identified in individuals with CEM (Bernstein et al. 2003), BID constitutes a plausible mediating pathway to account for the relationship between CEM and PSMU. Body image dissatisfaction, defined as "the 
discrepancy between identification of one's own figure (actual) and the figure one chose as the desirable self-image (ideal)" (Forrest and Stuhldreher 2007, p. 18), is inversely associated with self-esteem and positive mood (Grilo et al. 2005; Johnson and Wardle 2005). Individuals who have low self-esteem and who experience psychological distress are more vulnerable to feelings of dissatisfaction regarding their body image (Grilo et al. 2005). Since individuals who have been emotionally maltreated are more likely to feel flawed and/or develop unattainable perfection standards, they are more likely to develop negative self-schemata and BID (Neziroglu et al. 2006). This is especially the case during sensitive developmental periods such as adolescence, where experiencing different physical and cognitive developments may result in increased anxiety concerning physical appearance (Jones 2004), particularly among female adolescents (Hargreaves and Tiggemann 2004).

Individuals tend to cope with negative affect related to BID by using different maladaptive strategies (e.g., excessive eating, substance abuse) (Mitchison et al. 2017; Nieri et al. 2005). Past research has identified that some individuals engage in problematic internet use to avoid or relieve psychopathological symptoms (Lemenager et al. 2018; Wegmann et al. 2018), and/or to cope with low self-esteem associated with BID symptoms (Koronczai et al. 2013). This is in line with the proposition that emotional problems (e.g., depression or anxiety symptoms) play a pivotal role in the emergence of problematic online behaviors (Kardefelt-Winther 2014; Wegmann and Brand 2016). Therefore, it is both theoretically and empirically reasonable to hypothesize that BID will be positively associated with PSMU and account for the relationship between CEM and PSMU.

Despite previous empirical evidence associating dysfunctional attachment and/or childhood trauma with problematic internet use and PSMU (Koronczai et al. 2013; Lemenager et al. 2018; Worsley et al. 2018), the direct and indirect relationship of CEM and BID with PSMU and remains unexplored. Based on the aforementioned rationale, the present study examined the direct and indirect association of CEM with PSMU via BID using a sample of adolescents (see Fig. 1), and separately according to gender. Indeed, previous studies have demonstrated gender differences among these variables. For instance, female adolescents generally perceive themselves having higher CEM, BID, and PSMU compared to males (e.g., Grogan 2016; Kuss and Griffiths 2011; Shaffer et al. 2009; Wekerle et al. 2009).

\section{Methods}

\section{Participants and Procedure}

A total of 385 adolescent social media users, aged between 14 and 18 years $\left(M_{\mathrm{age}}=15.62\right.$ years, $\mathrm{SD}=1.00,57 \%$ female), participated in the study. Participants were recruited from a high

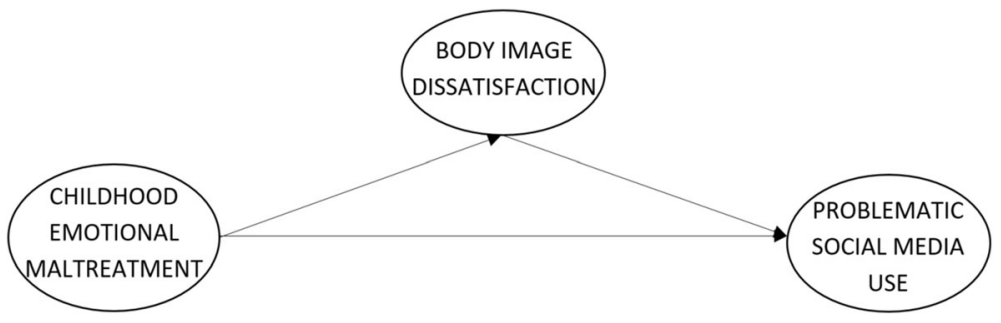

Fig. 1 Hypothesized model 
school in a north-western region of Turkey. The inclusion criterion for participation in the study was having an active social media account. All participants were informed about the details of the study and gave their informed consent. They were also informed that all their data would remain anonymous and confidential. Before data collection, necessary permissions for the study were taken from the ethical committee of the provincial directorate of national education, and complied with the Helsinki declaration. After providing the necessary information about the study, "paper-and-pencil" questionnaires were handed out to students in each classroom by the first author.

\section{Measures}

Social Media Use Questionnaire The Social Media Use Questionnaire (SMUQ) (Xanidis and Brignell 2016) comprises nine items assessing two factors of problematic use of social media, namely, withdrawal (e.g., "I feel anxious, when I am not able to check my social network account") and compulsion (e.g., "I lose track of time when I use SNS"). Previous studies with the Turkish form have reported optimal validity and reliability for the scale (Kircaburun et al. 2018). In the present study, PSMU was operationalized as a latent variable defined by the two factors of the SMUQ. Internal consistency was high in the present study (Cronbach's $\alpha=$ $0.85)$.

Childhood Trauma Questionnaire The Childhood Trauma Questionnaire (CTQ) (Bernstein et al. 1994; Bernstein et al. 1997) comprises 28 items scored on a 5-point Likert scale from "never true" to "very often true," and assesses five factors (five items for each factor): emotional neglect (e.g., "Felt loved"), emotional abuse (e.g., "Called names by family"), physical neglect, physical abuse, and sexual abuse. In the present study, and according to its objectives, only items relating to the emotional abuse and neglect factors were used. Previous studies have reported optimal validity and reliability of the scale (Sar et al. 2012). CEM was operationalized as a latent variable defined by the two relevant subfactors of the CTQ. Internal consistency was high in the present study (Cronbach's $\alpha=0.88$ ).

Body Image Dissatisfaction Scale The Body Image Dissatisfaction Scale (BIDS) was developed based on the Physical Appearance Self-Competence subscale of the Self-Perception Profile for Adolescents (Harter 2012) and comprises five items (e.g., "I am not pleased with my physical appearance," "I wish my physical appearance was different") scored on a 4-point Likert scale ranging from "absolutely disagree" to "very true." As the BIDS had not been previously validated in Turkish, exploratory and confirmatory analyses were conducted to ascertain the usability of the scale. Exploratory factor analysis (EFA; explaining 55\% of the variance) and confirmatory factor analysis (CFA; standardized regression weights ranging from 0.56 to 0.75$)$ indicated a unidimensional factor that presented an acceptable fit to the data $\left(\chi^{2} / d f=2.47, \mathrm{RMSEA}=0.06[\mathrm{CI} 90 \%(0.00,0.13)], \mathrm{CFI}=0.99, \mathrm{GFI}=0.99\right)$. Internal consistency was high in the present study (Cronbach's $\alpha=0.80$ ).

\section{Statistical Analysis}

Frequency and descriptive statistics, Pearson correlations, $t$-tests, EFA and CFA (to check the structural validity of the BIDS, see above), and structural equation modeling (SEM) were computed 
via using SPSS 23.0 and AMOS 23.0 software. For the CFA and SEM, goodness-of-fit criteria determined by $\mathrm{Hu}$ and Bentler (1999) were used to evaluate model fit. Accordingly, root-meansquare residuals (RMSEA) should be below 0.05 , and comparative fit index (CFI) and goodness-offit index (GFI) should be above 0.95 for a good fit. RMSEA lower than 0.08, CFI higher than 0.90, and GFI higher than 0.90 are thresholds for acceptable fit. Total, direct, and indirect effects of independent and mediator variables on the outcome variable were calculated via using bootstrapping method with 5000 bootstrap samples and $95 \%$ bias-corrected confidence intervals.

\section{Results}

Frequency of participants' gender, daily social media use duration, and most popular social media platforms used are listed in Table 1. Students were asked to report their three most intensely used social media platforms from seven choices (see Table 1). Results indicated that Instagram (88\%) was the most popularly used platform among adolescents, followed by Whatsapp (85\%) and YouTube (64\%).

Correlation coefficients among the total sample, males, and females are presented in Tables 2 and 3. All study variables were positively correlated with each other, except for CEM and BID among the female subsample. Results of the $t$-tests regarding the differences between males and females are presented in Table 4. All study variables differed significantly between male and female adolescents. Female adolescents had significantly higher PSMU, CEM, and BID scores than male adolescents.

In order to test the hypothesized model (see Fig. 1), path analysis was applied while adjusting for gender, age, and daily social media use with the total sample (see Fig. 2), males only (see Fig. 3), and females only (see Fig. 4). Results demonstrated that all three mediation models with total sample $\left(\chi^{2} / d f=3.00, \mathrm{RMSEA}=0.07(\mathrm{CI} 90 \%[0.06,0.09]), \mathrm{CFI}=0.94\right.$, GFI $\left.=0.95\right)$, males $\left(\chi^{2} / d f=1.26, \mathrm{RMSEA}=0.04(\mathrm{CI} 90 \%\right.$ [0.00, 0.07]), CFI $=0.98, \mathrm{GFI}=0.96)$, and females $\left(\chi^{2} /\right.$ $d f=2.33, \mathrm{RMSEA}=0.08(\mathrm{CI} 90 \%[0.06,0.10]), \mathrm{CFI}=0.94, \mathrm{GFI}=0.94)$ indicated adequate-togood fit to the data.

Table 1 Demographic features of the participants $(n=385)$

$\%(n)$

\begin{tabular}{lc}
\hline Gender & $57(222)$ \\
Male & $43(164)$ \\
Female & \\
Daily social media use time & $30(116)$ \\
Less than $2 \mathrm{~h}$ & $49(188)$ \\
$2-4 \mathrm{~h}$ & $21(81)$ \\
More than $4 \mathrm{~h}$ & $88(339)$ \\
Most popular social media platforms & $85(327)$ \\
Instagram & $64(247)$ \\
WhatsApp & $21(82)$ \\
YouTube & $13(48)$ \\
Snapchat & $11(43)$ \\
Google+ & $10(40)$ \\
Twitter & $10(10)$ \\
Facebook &
\end{tabular}

Note: Participants were asked to choose their three most often used platforms out of seven 
Table 2 Pearson correlation coefficients of the study variables among total sample $(n=385)$

1. 2 .

1. Problematic social media use

2. Childhood emotional maltreatment

3. Body image dissatisfaction
$-$

$0.23 * * *$

$0.27 * * *$
$0.21 * * *$

$* * * p<0.001$

CEM was indirectly associated with PSMU via BID among the total sample $(\beta=0.06$, $p<0.01,95 \%$ CI $[0.01,0.12])$ and among males $(\beta=0.07, p<0.05,95 \% \mathrm{CI}[0.01,0.16])$. BID fully mediated the relationship between CEM and PSMU, although the total effect of CEM on PSMU was small among both the total sample $(\beta=0.16, p<0.05,95 \%$ CI $[0.01,0.30])$ and in males $(\beta=0.24, p<0.05,95 \%$ CI $[0.03,0.43])$. However, BID, but not CEM, was positively associated with PSMU among females $(\beta=0.20, p<0.05,95 \%$ CI $[0.03,0.34])$. CEM was not found to have an effect on female adolescents' BID and PSMU. Daily social media use, which was adjusted for PSMU in the models, was associated with PSMU among all three samples. The mediation models explained $47 \%$ to $51 \%$ of the variance of PSMU.

\section{Discussion}

The present study examined a potential mediational pathway between CEM and PSMU in a sample of adolescents, and separately according to gender. CEM was indirectly associated with PSMU via BID among males, although only BID, but not CEM, had a significant effect on PSMU among females.

CEM has been shown to predict problematic internet use (Dalbudak et al. 2014) and problematic social media use (Worsley et al. 2018) in previous empirical studies. The present study supported the proposition that PSMU may constitute a maladaptive coping strategy to cope with emotional trauma and body dissatisfaction (adolescent boys) or body dissatisfaction (adolescent girls). This indicates that PSMU is directly or indirectly related to both CEM and BID only in male adolescents. This finding suggests that male and female adolescents appear to cope with their adverse childhood experiences differently. Male adolescents who have experienced CEM may develop higher BID, and in turn develop PSMU in order to cope with the related negative affect (Kostanski and Gullone 1998). The situation appeared to be different for female adolescents, as emphasized by the model which failed to identify a direct association between CEM and BID among females. This specific finding is in accordance with a previous cross-sectional study conducted with female adolescents showing that peer and media

Table 3 Pearson correlation coefficients of the study variables among males and females

\begin{tabular}{llll}
\hline & 1. & 2. & 3. \\
\hline 1. Problematic social media use & - & $\mathbf{0 . 2 1 * *}$ & $\mathbf{0 . 2 0 * *}$ \\
2. Childhood emotional maltreatment & $0.24 * *$ & - & $\mathbf{0 . 2 3} * *$ \\
3. Body image dissatisfaction & $0.33^{* * *}$ & 0.12 & - \\
\hline
\end{tabular}

Note. Correlation coefficients on the left side of the table belong to male adolescents while coefficients in bold belong to female adolescents

$* * p<0.01, * * * p<0.001$ 
Table 4 Comparison of the scores of study variables ( $t$-test) between males and females

\begin{tabular}{|c|c|c|c|c|c|}
\hline & $\begin{array}{l}\text { Total sample } \\
(n=385)\end{array}$ & $\begin{array}{l}\text { Males } \\
(n=163)\end{array}$ & $\begin{array}{l}\text { Females } \\
(n=222)\end{array}$ & $t$-test & $\begin{array}{l}\text { Cohen's } \\
d\end{array}$ \\
\hline Problematic social media use & $24.30 \pm 7.73$ & $22.48 \pm 7.07$ & $25.66 \pm 7.93$ & $-4.07 * * *$ & 0.42 \\
\hline $\begin{array}{l}\text { Childhood emotional } \\
\text { maltreatment }\end{array}$ & $15.85 \pm 6.96$ & $14.78 \pm 5.64$ & $16.65 \pm 7.72$ & $-2.63^{* *}$ & 0.28 \\
\hline Body image dissatisfaction & $11.33 \pm 3.25$ & $10.77 \pm 2.96$ & $11.75 \pm 3.39$ & $-2.95 * *$ & 0.31 \\
\hline
\end{tabular}

Note. $* * p<0.01, * * * p<0.001 ;$ mean $\pm \mathrm{SD}$

influences (e.g., attractive celebrity and peer images) constituted stronger predictors than parental influences of BID symptoms and eating disorders (Shroff and Thompson 2006). It is also consistent with empirical evidence showing that females are more prone to be adversely affected by peer and media influence than males (Brown and Tiggemann 2016; Nesi and Prinstein 2015).

Various types of psychological factors may account for the relationships observed in the present study. For instance, it has been shown that ruminative thinking mediates the relationship between psychopathological symptoms and addictive use of smartphones, which are heavily used for social networking (Elhai et al. 2018). Another psychological process that may mediate the associations observed is impulsivity, which has been implicated with PSMU (Rothen et al. 2018) and with many excessive and addictive-like behaviors (e.g., buying) that can also be used to cope with negative emotions and affect (Lucas and Koff 2017; Kuss and Griffiths 2017). Given the important inverse relationship between secure attachment (which is negatively related to BID) and online addictions

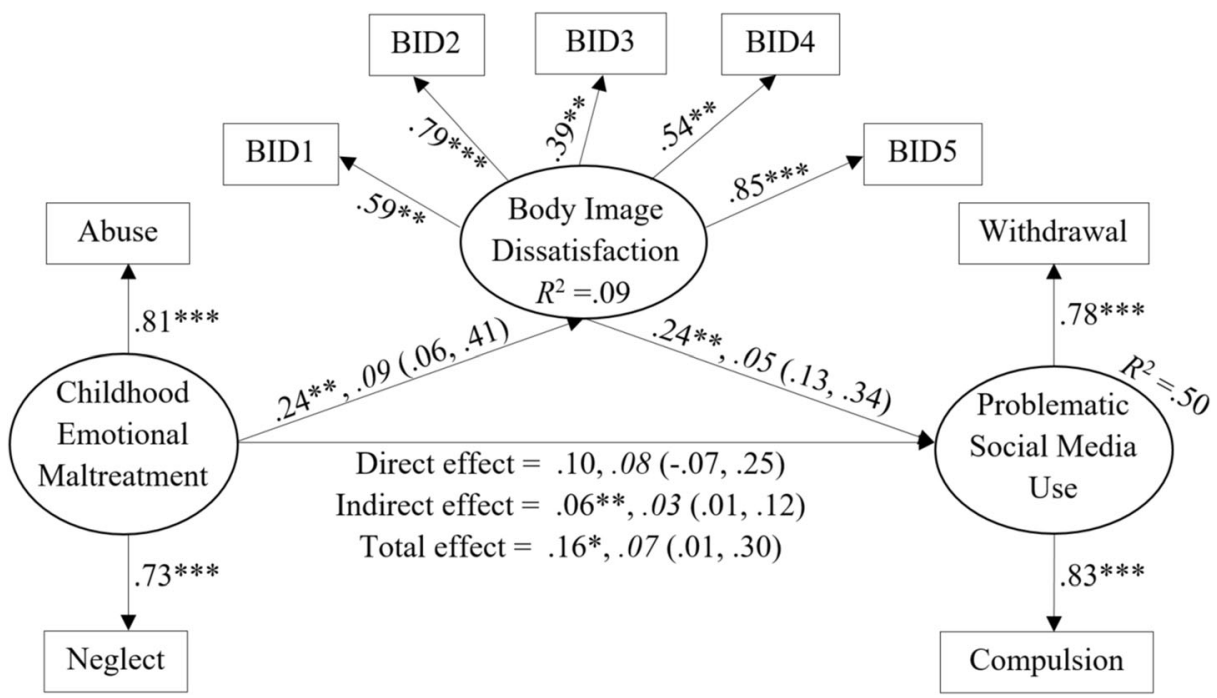

Fig. 2 Final model of the significant path coefficients between variables among total sample. Latent variables are represented in the model by circles while observed variables are represented by rectangles. Path coefficients are given on the left and standardized errors are written italic while 95\% confidence intervals are given in the brackets. For clarity, control variables (gender, age, and daily social media use) have not been depicted in the figure. Gender was negatively associated with problematic social media use $(\beta=-0.10, p<0.05,95 \%$ CI $[-0.19$, $-0.00])$, social media use was positively associated with it $(\beta=0.57, p<0.001,95 \% \mathrm{CI}[0.48,0.66])$ while age was not $(\beta=-0.05, p>0.05,95 \%$ CI $[-0.13,0.05]) .{ }^{*} p<0.05, * * p<0.01, * * * p<0.001$ 


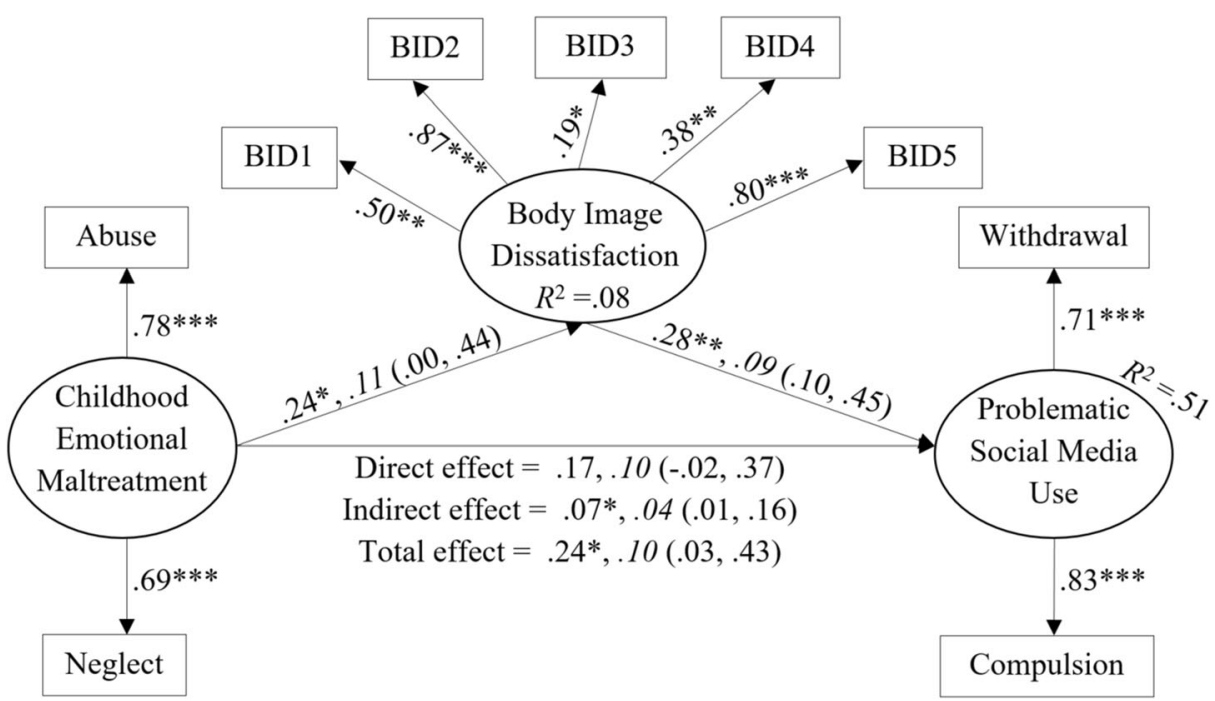

Fig. 3 Final model of the significant path coefficients between variables among males. Latent variables are represented in the model by circles while observed variables are represented by rectangles. Path coefficients are given on the left side and standardized errors are written italic while $95 \%$ confidence intervals are given in the brackets. For clarity, control variables (daily social media use and age) have not been depicted in the figure. Social media use was positively associated with problematic social media use $(\beta=0.53, p<0.001,95 \%$ CI $[0.40$, $0.66])$ while age was not $(\beta=-0.12, p>0.05,95 \%$ CI $[-0.27,0.03]) * p<0.05, * * p<0.01, * * * p<0.001$

(Monacis et al. 2017), body image satisfaction can be viewed as a protective factor against the onset and development of PSMU (Barnes and Caltabiano 2017).

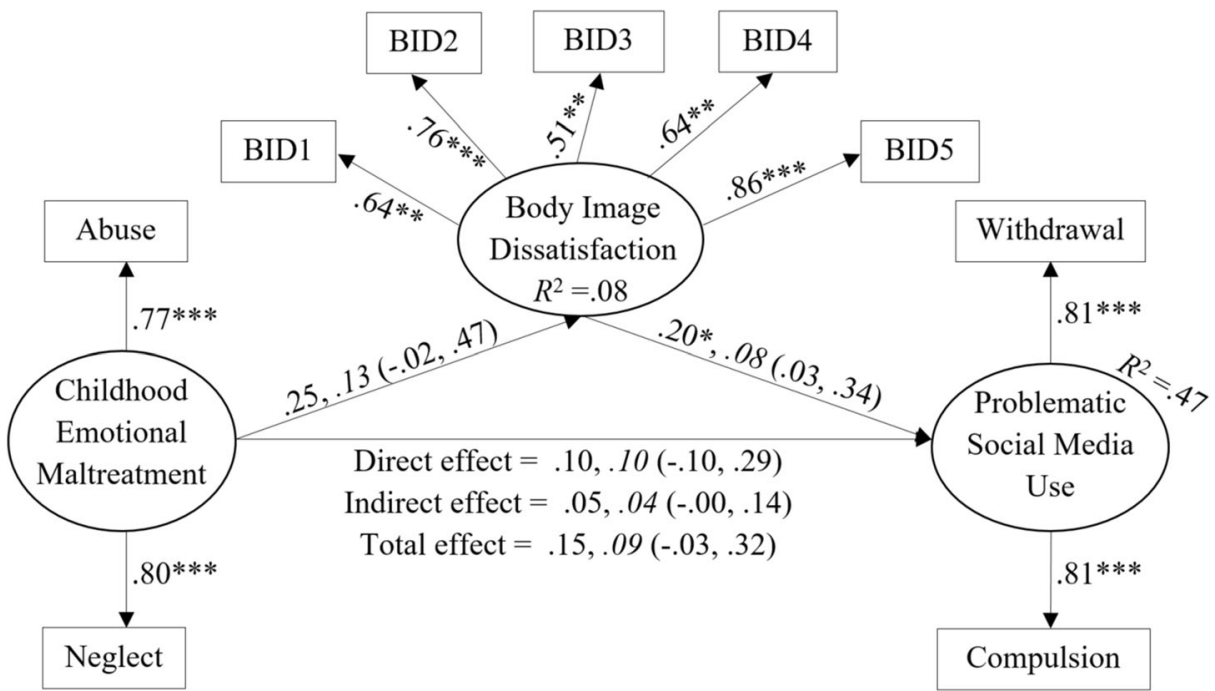

Fig. 4 Final model of the significant path coefficients between variables among females. Latent variables are represented in the model by circles while observed variables are represented by rectangles. Path coefficients are given on the left and standardized errors are written italic. The $95 \%$ confidence intervals are given in the brackets. For clarity, control variables (daily social media use and age) have not been depicted in the figure. Social media use was positively associated with problematic social media use $(\beta=0.60, p<0.001,95 \%$ CI $[0.49,0.71])$ while age was not $(\beta=-0.01, p>0.05,95 \%$ CI $[-0.13,0.11]) .{ }^{*} p<0.05, * * p<0.01, * * * p<0.001$ 
The present study is not without limitations. First, the cross-sectional design prevents the drawing of conclusions concerning causal relationships. In order to be able to indicate causality and directions of these relationships, future studies need to employ longitudinal designs. Second, the research data were collected via self-report questionnaires which are known to be affected by various response biases. Third, the sample was self-selected, comprised only Turkish adolescents, and modest in size, which compromises the generalizability of the findings. Future studies should thus explore the mediational pathways identified using a longitudinal design and carried out using a representative sample including adolescents from more than one single high school. Future studies should also replicate the present findings by using different age groups and individuals from other countries and cultures.

Despite its limitations, the present study is the first to examine the direct and indirect associations between CEM and PSMU via BID. The findings of the present study suggest that CEM is indirectly associated with PSMU via BID among males and that BID is positively associated with PSMU in both male and female adolescents. The present study opens up a new perspective in terms of prevention and intervention of adolescent PSMU based on gender.

\section{Compliance with Ethical Standards}

Conflict of Interest The authors declare that they have no conflict of interest.

Ethical Approval All procedures performed in this study involving human participants were in accordance with the ethical standards of University's Research Ethics Board and with the 1975 Helsinki Declaration.

Informed Consent Informed consent was obtained from all participants.

Open Access This article is distributed under the terms of the Creative Commons Attribution 4.0 International License (http://creativecommons.org/licenses/by/4.0/), which permits unrestricted use, distribution, and reproduction in any medium, provided you give appropriate credit to the original author(s) and the source, provide a link to the Creative Commons license, and indicate if changes were made.

Publisher's note Springer Nature remains neutral with regard to jurisdictional claims in published maps and institutional affiliations.

\section{References}

Baggio, S., Starcevic, V., Studer, J., Simon, O., Gainsbury, S. M., Gmel, G., \& Billieux, J. (2018). Technologymediated addictive behaviors constitute a spectrum of related yet distinct conditions: A network perspective. Psychology of Addictive Behaviors, 32, 564-572.

Balakrishnan, J., \& Griffiths, M. D. (2017). Social media addiction: What is the role of content in YouTube? Journal of Behavioral Addictions, 6, 364-377.

Barnes, M. A., \& Caltabiano, M. L. (2017). The interrelationship between orthorexia nervosa, perfectionism, body image and attachment style. Eating and Weight Disorders-Studies on Anorexia, Bulimia and Obesity, 22, 177-184.

Bernstein, D. P., Fink, L., Handelsman, L., Foote, J., Lovejoy, M., Wenzel, K., ... \& Ruggiero, J. (1994). Initial reliability and validity of a new retrospective measure of child abuse and neglect. American Journal of Psychiatry, 151, 1132. 
Bernstein, D. P., Ahluvalia, T., Pogge, D., \& Handelsman, L. (1997). Validity of the childhood trauma questionnaire in an adolescent psychiatric population. Journal of the American Academy of Child \& Adolescent Psychiatry, 36, 340-348.

Bernstein, D. P., Stein, J. A., Newcomb, M. D., Walker, E., Pogge, D., Ahluvalia, T., Stokes, J., Handelsman, L., Medrano, M., Desmond, D., \& Zule, W. (2003). Development and validation of a brief screening version of the childhood trauma questionnaire. Child Abuse \& Neglect, 27, 169-190.

Brand, M., Young, K. S., Laier, C., Wölfling, K., \& Potenza, M. N. (2016). Integrating psychological and neurobiological considerations regarding the development and maintenance of specific internet-use disorders: An interaction of person-affect-cognition-execution (I-PACE) model. Neuroscience \& Biobehavioral Reviews, 71, 252-266.

Brown, Z., \& Tiggemann, M. (2016). Attractive celebrity and peer images on Instagram: Effect on women's mood and body image. Body Image, 19, 37-43.

Carbonell, X., \& Panova, T. (2017). A critical consideration of social networking sites' addiction potential. Addiction Research \& Theory, 25, 48-57.

Dalbudak, E., Evren, C., Aldemir, S., \& Evren, B. (2014). The severity of internet addiction risk and its relationship with the severity of borderline personality features, childhood traumas, dissociative experiences, depression and anxiety symptoms among Turkish university students. Psychiatry Research, 219, 577-582.

Didie, E. R., Tortolani, C. C., Pope, C. G., Menard, W., Fay, C., \& Phillips, K. A. (2006). Childhood abuse and neglect in body dysmorphic disorder. Child Abuse \& Neglect, 30, 1105-1115.

Elhai, J. D., Tiamiyu, M., \& Weeks, J. (2018). Depression and social anxiety in relation to problematic smartphone use: The prominent role of rumination. Internet Research, 28, 315-332.

Forrest, K. Y., \& Stuhldreher, W. L. (2007). Patterns and correlates of body image dissatisfaction and distortion among college students. American Journal of Health Studies, 22, 18-25.

Grilo, C. M., Masheb, R. M., Brody, M., Burke-Martindale, C. H., \& Rothschild, B. S. (2005). Binge eating and self-esteem predict body image dissatisfaction among obese men and women seeking bariatric surgery. International Journal of Eating Disorders, 37, 347-351.

Grogan, S. (2016). Body image: Understanding body dissatisfaction in men, women and children. New York: Taylor \& Francis.

Hagborg, J. M., Tidefors, I., \& Fahlke, C. (2017). Gender differences in the association between emotional maltreatment with mental, emotional, and behavioral problems in Swedish adolescents. Child Abuse \& Neglect, 67, 249-259.

Hamilton, J. L., Shapero, B. G., Stange, J. P., Hamlat, E. J., Abramson, L. Y., \& Alloy, L. B. (2013). Emotional maltreatment, peer victimization, and depressive versus anxiety symptoms during adolescence: Hopelessness as a mediator. Journal of Clinical Child \& Adolescent Psychology, 42, 332-347.

Hargreaves, D. A., \& Tiggemann, M. (2004). Idealized media images and adolescent body image: "Comparing" boys and girls. Body Image, 1, 351-361.

Harter, S. (2012). Self-perception profile for adolescents: Manual and questionnaires. Denver: University of Denver.

Horzum, M. B. (2016). Examining the relationship to gender and personality on the purpose of Facebook usage of Turkish university students. Computers in Human Behavior, 64, 319-328.

Hu, L. T., \& Bentler, P. M. (1999). Cutoff criteria for fit indexes in covariance structural analysis: Conventional criteria versus new alternatives. Structural Equation Modeling, 6, 1-55.

Johnson, F., \& Wardle, J. (2005). Dietary restraint, body dissatisfaction, and psychological distress: A prospective analysis. Journal of Abnormal Psychology, 114, 119-125.

Jones, D. C. (2004). Body image among adolescent girls and boys: A longitudinal study. Developmental Psychology, 40, 823-835.

Kardefelt-Winther, D. (2014). A conceptual and methodological critique of internet addiction research: Towards a model of compensatory internet use. Computers in Human Behavior, 31, 351-354.

Kessler, R. C., McLaughlin, K. A., Green, J. G., Gruber, M. J., Sampson, N. A., Zaslavsky, A. M., AguilarGaxiola, S., Alhamzawi, A. O., Alonso, J., Angermeyer, M., Benjet, C., Bromet, E., Chatterji, S., de Girolamo, G., Demyttenaere, K., Fayyad, J., Florescu, S., Gal, G., Gureje, O., Haro, J. M., Hu, C. Y., Karam, E. G., Kawakami, N., Lee, S., Lépine, J. P., Ormel, J., Posada-Villa, J., Sagar, R., Tsang, A., Üstün, T. B., Vassilev, S., Viana, M. C., \& Williams, D. R. (2010). Childhood adversities and adult psychopathology in the WHO world mental health surveys. British Journal of Psychiatry, 197, 378-385.

Kurcaburun, K., \& Griffiths, M. D. (2018). Instagram addiction and the big five of personality: The mediating role of self-liking. Journal of Behavioral Addictions, 7, 158-170.

Kircaburun, K., Alhabash, S., Tosuntaș, Ș. B., \& Griffiths, M. D. (2018). Uses and gratifications of problematic social media use among university students: A simultaneous examination of the big five of personality traits, social media platforms and social media use motives. International Journal of Mental Health and Addiction. https://doi.org/10.1007/s11469-018-9940-6. 
Koronczai, B., Kökönyei, G., Urbán, R., Kun, B., Pápay, O., Nagygyörgy, K., Griffiths, M. D., \& Demetrovics, Z. (2013). The mediating effect of self-esteem, depression and anxiety between satisfaction with body appearance and problematic internet use. American Journal of Drug and Alcohol Abuse, 39, 259-265.

Kostanski, M., \& Gullone, E. (1998). Adolescent body image dissatisfaction: Relationships with self-esteem, anxiety, and depression controlling for body mass. The Journal of Child Psychology and Psychiatry and Allied Disciplines, 39, 255-262.

Kuss, D. J., \& Griffiths, M. D. (2011). Online social networking and addiction - A review of the psychological literature. International Journal of Environmental Research and Public Health, 8, 3528-3552.

Kuss, D. J., \& Griffiths, M. D. (2017). Social networking sites and addiction: Ten lessons learned. International Journal of Environmental Research and Public Health, 14, 311.

Lemenager, T., Hoffmann, S., Dieter, J., Reinhard, I., Mann, K., \& Kiefer, F. (2018). The links between healthy, problematic, and addicted internet use regarding comorbidities and self-concept-related characteristics. Journal of Behavioral Addictions, 7, 31-43.

Lucas, M., \& Koff, E. (2017). Body image, impulse buying, and the mediating role of negative affect. Personality and Individual Differences, 105, 330-334.

Maguire, S. A., Williams, B., Naughton, A. M., Cowley, L. E., Tempest, V., Mann, M. K., ... \& Kemp, A. M. (2015). A systematic review of the emotional, behavioural and cognitive features exhibited by school-aged children experiencing neglect or emotional abuse. Child: Care, Health and Development, 41, 641-653.

Merriam-Webster Dictionary (2018). Definition of social media. Accessed October 30, 2018, from https://www. merriam-webster.com/dictionary/social\%20media.

Mills, P., Newman, E. F., Cossar, J., \& Murray, G. (2015). Emotional maltreatment and disordered eating in adolescents: Testing the mediating role of emotion regulation. Child Abuse \& Neglect, 39, 156-166.

Mitchison, D., Hay, P., Griffiths, S., Murray, S. B., Bentley, C., Gratwick-Sarll, K., Harrison, C., \& Mond, J. (2017). Disentangling body image: The relative associations of overvaluation, dissatisfaction, and preoccupation with psychological distress and eating disorder behaviors in male and female adolescents. International Journal of Eating Disorders, 50, 118-126.

Monacis, L., de Palo, V., Griffiths, M. D., \& Sinatra, M. (2017). Exploring individual differences in online addictions: The role of identity and attachment. International Journal of Mental Health and Addiction, 15, 853-868.

Montag, C., Bey, K., Sha, P., Li, M., Chen, Y. F., Liu, W. Y., Zhu, Y. K., Li, C. B., Markett, S., Keiper, J., \& Reuter, M. (2015). Is it meaningful to distinguish between generalized and specific internet addiction? Evidence from a cross-cultural study from Germany, Sweden, Taiwan and China. Asia-Pacific Psychiatry, 7, 20-26.

Nesi, J., \& Prinstein, M. J. (2015). Using social media for social comparison and feedback-seeking: Gender and popularity moderate associations with depressive symptoms. Journal of Abnormal Child Psychology, 43, $1427-1438$.

Neziroglu, F., Khemlani-Patel, S., \& Yaryura-Tobias, J. A. (2006). Rates of abuse in body dysmorphic disorder and obsessive-compulsive disorder. Body Image, 3, 189-193.

Nieri, T., Kulis, S., Keith, V. M., \& Hurdle, D. (2005). Body image, acculturation, and substance abuse among boys and girls in the southwest. American Journal of Drug and Alcohol Abuse, 31, 617-639.

Rothen, S., Briefer, J.-F., Deleuze, J., Karila, L., Andreassen, C. S., Achab, S., Thorens, G., Khazaal, Y., Zullino, D., \& Billieux, J. (2018). Disentangling the role of users' preferences and impulsivity traits in problematic Facebook use. PLoS ONE, 13, e0201971.

Sansone, R. A., Sansone, L. A., \& Wiederman, M. (1995). The prevalence of trauma and its relationship to borderline personality symptoms and self-destructive behaviors in a primary care setting. Archives of Family Medicine, 4, 439-442.

Sar, V., Öztürk, P. E., \& İkikardeș, E. (2012). Validity and reliability of the Turkish version of childhood trauma questionnaire. Turkiye Klinikleri Journal of Medical Sciences, 32, 1054-1063.

Schimmenti, A., \& Caretti, V. (2010). Psychic retreats or psychic pits?: Unbearable states of mind and technological addiction. Psychoanalytic Psychology, 27, 115-132.

Schimmenti, A., Passanisi, A., Caretti, V., La Marca, L., Granieri, A., Iacolino, C., et al. (2017). Traumatic experiences, alexithymia, and internet addiction symptoms among late adolescents: A moderated mediation analysis. Addictive Behaviors, 64, 314-320.

Shaffer, A., Yates, T. M., \& Egeland, B. R. (2009). The relation of emotional maltreatment to early adolescent competence: Developmental processes in a prospective study. Child Abuse \& Neglect, 33, 36-44.

Shroff, H., \& Thompson, J. K. (2006). The tripartite influence model of body image and eating disturbance: A replication with adolescent girls. Body Image, 3, 17-23.

Statista. (2017). Social media statistics \& facts. Accessed October 30, 2018, From https://www.statista. com/topics/1164/social-networks/. 
Thege, B. K., Horwood, L., Slater, L., Tan, M. C., Hodgins, D. C., \& Wild, T. C. (2017). Relationship between interpersonal trauma exposure and addictive behaviors: A systematic review. BMC Psychiatry, 17, 164.

Wegmann, E., \& Brand, M. (2016). Internet-communication disorder: It's a matter of social aspects, coping, and internet-use expectancies. Frontiers in Psychology, 7, 1747.

Wegmann, E., Ostendorf, S., \& Brand, M. (2018). Is it beneficial to use internet-communication for escaping from boredom? Boredom proneness interacts with cue-induced craving and avoidance expectancies in explaining symptoms of internet-communication disorder. PLOS ONE, 13, e0195742.

Wekerle, C., Leung, E., Wall, A. M., MacMillan, H., Boyle, M., Trocme, N., \& Waechter, R. (2009). The contribution of childhood emotional abuse to teen dating violence among child protective services-involved youth. Child Abuse \& Neglect, 33, 45-58.

Worsley, J. D., McIntyre, J. C., Bentall, R. P., \& Corcoran, R. (2018). Childhood maltreatment and problematic social media use: The role of attachment and depression. Psychiatry Research, 267, 88-93.

Xanidis, N., \& Brignell, C. M. (2016). The association between the use of social network sites, sleep quality and cognitive function during the day. Computers in Human Behavior, 55, 121-126. 